\title{
The influence of vaginal progesterone on Uterine Artery Pulsatility Index
}

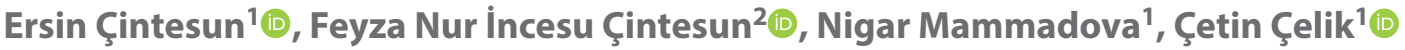 \\ ${ }^{1}$ Department of Obstetrics and Gynecology, Faculty of Medicine, Selcuk University, Konya, Turkey \\ ${ }^{2}$ Konya Research and Training Hospital, Meram, Konya, Turkey
}

\begin{abstract}
Objectives: Uterine artery Doppler is frequently used in the first trimester and it is one of the more effective measurement methods in the prediction of preeclampsia and intrauterine growth restriction (IUGR). Progesterone is a hormone that is used quite frequently in various indications in obstetrics and gynecologic practice. We aimed to investigate the influence of progesterone on the uterine artery Doppler pulsatility index (PI) at 11-14 gestational weeks.

Material and methods: This study is a retrospective case-control study conducted in Selcuk University Faculty of Medicine between January and December 2019. Uterine artery Doppler PI values of patients using progesterone were compared with $\mathrm{PI}$ values of patients not using progesterone. Uterine artery PI was measured two times, left and right. Then the mean PI was calculated. All measurements were made by two operators and by the same ultrasonography machine

Results: A total of 288 patients, 140 patients using progesterone and 148 patients not using progesterone were included in the study. Demographic characteristics were similar between the groups $(p>0.05)$. There were no significant differences between the groups in the right and left uterine artery PI values. There was no significant difference for average uterine artery PI between the groups $(p<0.05)$.

Conclusions: Progesterone has no significant influence on uterine artery PI. However, more prospective studies in which all potential confounding factors are considered including serum progesterone levels are needed for this subject.
\end{abstract}

Key words: uterine artery; preeclampsia; progesterone; pulsatility index

Ginekologia Polska 2021; 92, 6: 436-439

\section{INTRODUCTION}

Many functional and structural uterine vascular system changes occur in pregnancy. The basis of the changes in the uterine artery is the trophoblastic invasion of the spiral arteries, and these changes provide the fetus with a greater blood supply [1]. Incorrect changes in the spiral arteries may cause insufficient uteroplacental perfusion and this may lead to some complications, such as intrauterine growth restriction (IUGR), preeclampsia, spontaneous preterm delivery, and premature rupture of membranes [1, 2].

Preeclampsia is an important life-threatening disease for both the mother and fetus. The pathogenesis of this disease occurs as a result of a defect in the trophoblastic invasion of the placenta in the first trimester of pregnancy [2]. Preeclampsia is the most important cause of maternal and fetal morbidity and mortality in both developed and developing countries [3]. Unfortunately, there is still no ef- fective treatment other than delivery. Due to the increased fetal morbidity and mortality, especially in preterm pregnancies, preeclampsia prediction is very important. Many ultrasonographic and biochemical evaluations of preeclampsia predictions have been defined in the literature [4-6]. Uterine artery Doppler is a well-known diagnostic method for the prediction of preeclampsia [6, 7]. The uterine artery Doppler pulsatility index (PI) is used for the prediction of preeclampsia during the $11^{\text {th }}-14^{\text {th }}$ gestational weeks. Many studies indicate that preeclampsia development is more frequent in women with high uterine artery PI [6-10]. External factors affecting PI values of uterine artery Doppler have been investigated previously in the literature. The effects of parameters such as patient position and emptiness/fullness of bladder were explored [11, 12]. The relationship between progesterone use and uterine artery Doppler at the $11^{\text {th }}-14^{\text {th }}$ gestational weeks has not been specifically

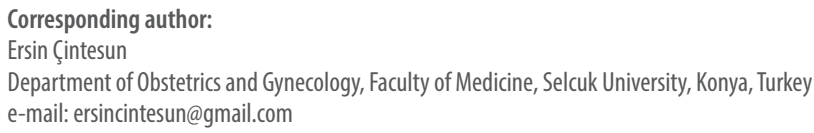


investigated in the literature. Progesterone is one of the main hormones in pregnancy, and it is used very often in obstetric practice. Therefore, we aimed to investigate the effect of progesterone use on uterine artery Doppler PI at the $11^{\text {th }}-14^{\text {th }}$ gestational weeks.

\section{MATERIAL AND METHODS}

This study is a retrospective case-control study conducted in Selcuk University Faculty of Medicine between January and December 2019. It was approved by the local ethics committee and conducted in accordance with the principles of the Helsinki Declaration (Reg.No:2020/022).

The patients between 18-45 years old and who had singleton pregnancy at $11+0$ to $13+6$ weeks of gestation with a normal fetus, without having systemic disease and treatment except vitamins, and using vaginal micronized progesterone for more than one week were included into the study. The exclusion criteria were the presence of hypertension, diabetes, vasculopathy, preeclampsia history, multiple pregnancies, usage of aspirin, and anticoagulant drug. Uterine artery Doppler PI values of progesterone users were compared with $\mathrm{PI}$ values of patients who were not using progesterone.

\section{Uterine artery Doppler measurement}

In our clinic, first trimester uterine artery Doppler is measured at 11-14 gestational weeks. The midsagittal section of the uterus and cervical canal is determined using transabdominal ultrasound. After the internal cervical canal is recognized, the uterine artery is determined by shifting the probe to both paracervical areas. During the measurement, it is acceptable to have 100-150 cc of urine in the bladder. When three similar consecutive waveforms are obtained, the right and left uterine artery PI values are recorded. It was measured two times, left and right. Then the mean PI was calculated. All measurements were made by two operators (NM and $\mathrm{EC}$ ) and by the same ultrasonography machine. (LOGIQ F8, General Electric Co.; Milwaukee, WI, USA). 95th percentile of the mean UA PI of the present study lied similar within the ranges recorded by Gómez et al. [13].

\section{Statistical Analysis}

Statistical analysis was performed using the Statistical Package for the Social Sciences (SPSS) version 21.0 software package (IBM Corp., Armonk, NY, USA). A histogram curve and Shapiro-Wilk analysis were used to check for normal distribution. Descriptive statistics are expressed in mean \pm standard deviation (SD), median (min-max), and number, where appropriate. Data were analyzed using the Mann-Whitney $U$ test, Student's t-test, and Pearson's chi-squared test. P values of $<0.05$ were considered statistically significant.

\section{RESULTS}

A total of 288 patients, 140 progesterone using patients and 148 patients not using progesterone were included in the study. All of the patients using progesterone in our study were patients using drugs due to the threat of miscarriage. There was no significant difference for age between the groups (mean $28.7 \pm 5.0$ vs $28.8 \pm 5.01$; $\mathrm{p}=0.885)$. Gestational age was no significant difference between the groups [median $12(11-13)$ vs 12 (11-13); $p=0.224]$. Gravida and parity were similar between the groups ( $p>0.05)$. There were no significant differences between the groups in terms of the right and left uterine artery $\mathrm{PI}$ values (mean $1.70 \pm 0.46$ vs $1.81 \pm 0.51 ; \mathrm{p}=0.062$, and mean $1.72 \pm 0.52$ vs $1.73 \pm 0.40 ; p=0.843$; respectively). There was no significant difference for average uterine artery PI between the groups (mean $1.71 \pm 0.40$ vs $1.77 \pm 0.37 ; p=0.184$ ). In five patients, the average uterine artery $\mathrm{PI}$ value was found to be greater than the $95^{\text {th }}$ percentile $(p>0.05)$ (Tab. 1).

\section{DISCUSSION}

Progesterone is a hormone that has a very important function both in the regulation of the menstrual cycle and in pregnancy. Progesterone is also one of the most commonly prescribed drugs during pregnancy. Uterine artery Doppler, measured between 11-14 weeks, has also been used recently in the prediction of preeclampsia. However, the interaction of these two conditions has not been specifically investigated in the literature. In our study, we found that the use of progesterone had no effect on bilateral uterine artery $\mathrm{PI}$.

The uterine artery is one of the main vessels of the uterus and fetus. During pregnancy, the spiral arteries are exposed to remodeling for providing enough blood supply to the

\begin{tabular}{|c|c|c|c|}
\hline \multirow{2}{*}{ Variables } & \multicolumn{2}{|c|}{ Progesterone use } & \multirow[b]{2}{*}{$p$ values } \\
\hline & $\begin{array}{l}\text { No } \\
n=140\end{array}$ & $\begin{array}{l}\text { Yes } \\
n=148\end{array}$ & \\
\hline Age & $28.7 \pm 5.0$ & $28.8 \pm 5.01$ & $0.885^{*}$ \\
\hline Gestational age & $12(11-13)$ & $12(11-13)$ & $0.224^{*}$ \\
\hline Gravida & $2(1-6)$ & $2(1-6)$ & $0.740^{+}$ \\
\hline Parity & $1(0-4)$ & $0(0-5)$ & $0.899^{+}$ \\
\hline RUA.PI & $1.70 \pm 0.46$ & $1.81 \pm 0.51$ & $0.062^{*}$ \\
\hline LUA.PI & $1.72 \pm 0.52$ & $1.73 \pm 0.40$ & $0.843^{*}$ \\
\hline AUA.PI & $1.71 \pm 0.40$ & $1.77 \pm 0.37$ & $0.184^{*}$ \\
\hline AUA.PI $>95^{\text {th }}$ centile & $4(2.9 \%)$ & $1(0.7 \%)$ & $0.157^{* *}$ \\
\hline
\end{tabular}

Data are given as mean $( \pm S D)$, number $(\%)$ or median (minimum-maximum) where appropriate; ${ }^{*}$ Independent Simple t-test; ${ }^{+}$Mann-Whitney U test;

**Pearson's chi-squared test; $\mathrm{PI}$ — pulsatility index; RUA.PI — right uterine artery PI; LUA.PI — left uterine artery PI; AUA.PI — average uterine artery PI 
fetus. Makikalio et al. demonstrated that in uncomplicated pregnancies, a progressive decrease began in the spiral artery $\mathrm{PI}$ at the fifth week gestation [14]. The impaired remodeling process can result in further pregnancy complications such as IUGR or pregnancy-induced hypertension. There are many studies claiming that these changes in the uterine artery can be used to predict preeclampsia [6, 7]. In a meta-analysis of Velauthan et al. on about 55,000 pregnant women, they found that first-trimester uterine artery Doppler was a useful tool for predicting early-onset pre-eclampsia and other adverse pregnancy outcomes [15]. In the present study, we investigated whether a common agent such as progesterone had a confounding effect on uterine artery Doppler. We found no effect of progesterone use on uterine artery Doppler PI.

Progesterone is used quite frequently in various indications in obstetrics and gynecologic practice. Although the effect of progesterone on the uterine artery in non-pregnant women is known, there is limited and conflicting information in the literature regarding its effect on pregnant women. Micronized progesterone is frequently used during pregnancy, it has a direct effect on the uterus and has higher concentrations in the uterine tissue. In addition, its vaginal form is superior to the oral form; although it reaches a faster plasma peak level in oral intake, more constant drug concentrations are observed in vaginal use $[16,17]$. Progesterone is effectively used for the prevention of threatened miscarriage, preterm labor, preterm birth in women with a short cervix, luteal deficiency, and recurrent miscarriage [18-23].

Czajkowski et al. [24] found that vaginal progesterone administration resulted in a decrease in spiral artery PI in early pregnancy complicated by threatened abortion. In addition, they found that vaginal progesterone treatment was associated with a significant decrease in the spiral artery PI after 2 weeks' and 4 weeks' treatment. In a study conducted by Jamal et al. [25] on pregnant women at 18-20 weeks of gestation, it was found that the use of progesterone and aspirin had a significant effect on uterine artery PI, and they found that vaginal progesterone use suppressed the resistance of uterine artery. Maged et al. [26] found that the use of progesterone for one week in patients in the third trimester had no significant effects on uterine artery PI. In this study, our hypothesis was that progesterone use might be a confounding factor on the uterine artery PI while predicting preeclampsia in the first trimester, but it was shown that progesterone use had no significant effect on uterine artery Doppler.

The retrospective design, unknown serum progesterone levels, and lack of long-term follow-up outcomes are limitations of this study. The strength of this study is that the effect of progesterone, a hormone commonly used at 11-14 weeks of gestation, on uterine artery Doppler, has not been investigated previously.

\section{CONCLUSIONS}

In conclusion, progesterone has no significant effect on uterine artery PI at 11-14 weeks of gestation. However, prospective studies are needed for this issue, where all potential confounding effects are considered, such as serum progesterone levels.

\section{Conflict of interest}

The authors declare that they have no conflict of interest.

\section{Ethical approval}

All procedures performed in studies involving human participants were in accordance with the ethical standards of the institutional and/or national research committee and with the 1964 Helsinki Declaration and its later amendments or comparable ethical standards.

\section{Financial disclosure}

The authors declared that this study has received no financial support.

\section{Informed consent}

Informed consent was obtained from all individual participants included in the study.

\section{REFERENCES}

1. Kim YM, Chaiworapongsa T, Gomez R, et al. Failure of physiologic trans formation of the spiral arteries in the placental bed in preterm premature rupture of membranes. Am J Obstet Gynecol. 2002; 187(5): 1137-1142, doi: 10.1067/mob.2002.127720, indexed in Pubmed: 12439491.

2. Zhou Y, Damsky CH, Fisher SJ. Preeclampsia is associated with failure of human cytotrophoblasts to mimic a vascular adhesion phenotype. One cause of defective endovascular invasion in this syndrome? J Clin Invest. 1997; 99(9): 2152-2164, doi: 10.1172/JCl119388, indexed in Pubmed: 9151787.

3. Neggers YH. Trends in maternal mortality in the United States. Reprod Toxicol. 2016; 64: 72-76, doi: 10.1016/j.reprotox.2016.04.001, indexed in Pubmed: 27063184.

4. Zeisler H, Llurba E, Chantraine F, et al. Predictive Value of the sFlt-1:PIGF Ratio in Women with Suspected Preeclampsia. N Engl J Med. 2016; 374(1): 13-22, doi: 10.1056/NEJMoa1414838, indexed in Pubmed: 26735990

5. Agrawal S, Cerdeira AS, Redman C, et al. Meta-Analysis and Systematic Review to Assess the Role of Soluble FMS-Like Tyrosine Kinase-1 and Placenta Growth Factor Ratio in Prediction of Preeclampsia: The SaPPPhirE Study. Hypertension. 2018; 71(2): 306-316, doi: 10.1161/HYPERTENSIONAHA.117.10182, indexed in Pubmed: 29229743.

6. Cnossen JS, Morris RK, ter Riet G, et al. Use of uterine artery Doppler ultrasonography to predict pre-eclampsia and intrauterine growth restriction: a systematic review and bivariable meta-analysis. CMAJ. 2008; 178(6): 701-711, doi: 10.1503/cmaj.070430, indexed in Pubmed: 18332385 .

7. Kleinrouweler CE, Bossuyt PMM, Thilaganathan B, et al. Value of adding second-trimester uterine artery Doppler to patient characteristics in identification of nulliparous women at increased risk for pre-eclampsia: an individual patient data meta-analysis. Ultrasound Obstet Gynecol. 2013; 42(3): 257-267, doi: 10.1002/uog.12435, indexed in Pubmed: 23417857.

8. Plasencia W, Maiz N, Poon L, et al. Uterine artery Doppler at $11+0$ to $13+6$ weeks in the prediction of pre-eclampsia. Ultrasound Obstet Gynecol. 2007; 30(5): 742-749, doi: 10.1002/uog.5157, indexed in Pubmed: 17899573. 
9. Kosiński P, Samaha RB, Bomba-Opoń DA, et al. Reference values for placental growth factor (PIGF) concentration and uterine artery doppler pulsatility index $(\mathrm{PI})$ at 11-13(+6) weeks of gestation in the Polish population. Ginekol Pol. 2014; 85(7): 488-493, doi: 10.17772/gp/1758, indexed in Pubmed: 25118498.

10. Tayyar A, Guerra L, Wright $A$, et al. Uterine artery pulsatility index in the three trimesters of pregnancy: effects of maternal characteristics and medical history. Ultrasound Obstet Gynecol. 2015; 45(6): 689-697, doi: 10.1002/uog.14789, indexed in Pubmed: 25594620.

11. Seravalli V, Masini G, Morelli $C$, et al. Impact of bladder filling on uterine artery Doppler variables in the first trimester of pregnancy. J Clin Ultrasound. 2019; 47(2): 83-87, doi: 10.1002/jcu.22649, indexed in Pubmed: 30393867.

12. Drouin $\mathrm{O}$, Johnson JA, Chaemsaithong $P$, et al. Transverse technique: complementary approach to measurement of first-trimester uterine artery Doppler. Ultrasound Obstet Gynecol. 2018; 52(5): 639-647, doi: 10.1002/uog.18917, indexed in Pubmed: 28976627.

13. Gómez $\mathrm{O}$, Figueras $\mathrm{F}$, Fernández $\mathrm{S}$, et al. Reference ranges for uterine artery mean pulsatility index at 11-41 weeks of gestation. Ultrasound Obstet Gynecol. 2008; 32(2): 128-132, doi: 10.1002/uog.5315, indexed in Pubmed: 18457355.

14. Mäkikallio K, Tekay A, Jouppila P. Uteroplacental hemodynamics during early human pregnancy: a longitudinal study. Gynecol Obstet Invest. 2004; 58(1): 49-54, doi: 10.1159/000077914, indexed in Pubmed: 15087597.

15. Velauthar L, Plana MN, Kalidindi M, et al. First-trimester uterine artery Doppler and adverse pregnancy outcome: a meta-analysis involving 55,974 women. Ultrasound Obstet Gynecol. 2014; 43(5): 500-507, doi: 10.1002/uog.13275, indexed in Pubmed: 24339044.

16. Fitzpatrick LA, Good A. Micronized progesterone: clinical indications and comparison with current treatments. Fertil Steril. 1999; 72(3): 389-397, doi: 10.1016/s0015-0282(99)00272-1, indexed in Pubmed: 10519605.

17. Nahoul K, Dehennin L, Scholler R. Radioimmunoassay of plasma progesterone after oral administration of micronized progesterone. J Steroid Biochem. 1987; 26(2): 241-249, doi: 10.1016/0022-4731(87)90078-1, indexed in Pubmed: 3560939.

18. Daya S. Luteal support: progestogens for pregnancy protection. Maturitas. 2009; 65 Suppl 1: S29-S34, doi: 10.1016/j.maturitas.2009.09.012, indexed in Pubmed: 19913373.
19. Sotiriadis A, Papatheodorou S, Makrydimas G. Threatened miscarriage: evaluation and management. BMJ. 2004; 329(7458): 152-155, doi: 10.1136/bmj.329.7458.152, indexed in Pubmed: 15258071.

20. Walch K, Hefler L, Nagele F. Oral dydrogesterone treatment during the first trimester of pregnancy: the prevention of miscarriage study (PROMIS). A double-blind, prospectively randomized, placebo-controlled, parallel group trial. J Matern Fetal Neonatal Med. 2005; 18(4): 265-269, doi: 10.1080/14767050500246243, indexed in Pubmed: 16318978.

21. Keçecioğlu M, Tokmak A, Keçecioğlu TS, et al. Does progesterone therapy increase nuchal translucency in women with threatened miscarriage? Ginekol Pol. 2016; 87(5): 390-394, doi: 10.5603/GP.2016.0010, indexed in Pubmed: 27304657.

22. Hassan SS, Romero R, Vidyadhari D, et al. PREGNANT Trial. Vaginal progesterone reduces the rate of preterm birth in women with a sonographic short cervix: a multicenter, randomized, double-blind, placebo-controlled trial. Ultrasound Obstet Gynecol. 2011;38(1): 18-31, doi: 10.1002/uog.9017, indexed in Pubmed: 21472815.

23. Wang $\mathrm{S}$, Wang $\mathrm{XT}$, Liu RH, et al. Dydrogesterone has no effect on uterine fibroids when used to prevent miscarriage in pregnant women with uterine fibroids. Ginekol Pol. 2017; 88(12): 679-685, doi: 10.5603/GP.a2017.0121, indexed in Pubmed: 29303226.

24. Czajkowski K, Sienko J, Mogilinski M, et al. Uteroplacental circulation in early pregnancy complicated by threatened abortion supplemented with vaginal micronized progesterone or oral dydrogesterone. Fertil Steril. 2007; 87(3): 613-618, doi: 10.1016/j.fertnstert.2006.07.1506, indexed in Pubmed: 17126337.

25. Jamal A, Moshfeghi M, Molaei B, et al. The effect of vaginal progesterone on Doppler findings in increased uterine artery resistance. J Matern Fetal Neonatal Med. 2019 [Epub ahead of print]: 1-4, doi: 10.1080/14767058.2019.1670794, indexed in Pubmed: 31665939.

26. Maged AM, Shoab AY, Hussein EA, et al. The Effect of Antenatal Vaginal Progesterone Administration on Uterine, Umbilical, and Fetal Middle Cerebral Artery Doppler Flow: A Cohort Study. Am J Perinatol. 2020; 37(5): 491-496, doi: 10.1055/s-0039-1683438, indexed in Pubmed: 30866028. 